\title{
Salicylate induces an antibiotic efflux pump in Burkholderia cepacia complex genomovar III (B. cenocepacia)
}

\author{
Bindu M. Nair, ${ }^{1}$ K-John Cheung, Jr., ${ }^{1}$ Adam Griffith, ${ }^{1}$ and Jane L. Burns ${ }^{1,2}$ \\ ${ }^{1}$ Division of Infectious Disease, Children's Hospital and Regional Medical Center, Seattle, Washington, USA \\ ${ }^{2}$ Department of Pediatrics, University of Washington, Seattle, Washington, USA
}

An antibiotic efflux gene cluster that confers resistance to chloramphenicol, trimethoprim, and
ciprofloxacin has been identified in Burkholderia cenocepacia (genomovar III), an important cystic
fibrosis pathogen. Five open reading frames have been identified in the cluster. There is apparently
a single transcriptional unit, with $l l p E$ encoding a lipase-like protein, ceoA encoding a putative
periplasmic linker protein, ceoB encoding a putative cytoplasmic membrane protein, and opcM encod-
ing a previously described outer membrane protein. A putative LysR-type transcriptional regulatory
gene, ceoR, is divergently transcribed upstream of the structural gene cluster. Experiments using radi-
olabeled chloramphenicol and salicylate demonstrated active efflux of both compounds in the pres-
ence of the gene cluster. Salicylate is an important siderophore produced by $B$. cepacia complex iso-
lates, and both extrinsic salicylate and iron starvation appear to upregulate ceoR promoter activity,
as does chloramphenicol. These results suggest that salicylate is a natural substrate for the efflux
pump in B. cenocepacia and imply that the environment of low iron concentration in the cystic fibro-
sis lung can induce efflux-mediated resistance, even in the absence of antibiotic selective pressure.

J. Clin. Invest. 113:464-473 (2004). doi:10.1172/JCI200419710.

\begin{abstract}
Introduction
Burkholderia cepacia complex strains are important pulmonary pathogens in patients with cystic fibrosis (CF). Although isolated from only $3.1 \%$ of patients over the age of 5 (1), this organism may be associated with severe morbidity and mortality in the CF population (2). B. cepacia complex is a group of related genomovars: phenotypically indistinguishable but genotypically identifiable strains (3). Nine distinct genospecies have been identified thus far, and eight have been given species names because they can now be identified in the clinical laboratory (4-6). Although virtually all genomovars have been isolated from individuals with $\mathrm{CF}$, most CF isolates are genomovars II and III, now called B. multivorans and $B$. cenocepacia, respectively $(7,8)$. Of these, $B$. cenocepacia has been most commonly associated with epidemic spread and increased clinical virulence $(9,10)$. Multiple antibiotic resistance is a characteristic of all $B$. cepacia complex isolates, particularly those from
\end{abstract}

Received for publication August 4, 2003, and accepted in revised form November 25, 2003.

Address correspondence to: Jane Burns, Division of Infectious Disease, 8G-1, Children's Hospital and Regional Medical Center, 4800 Sand Point Way NE, Seattle, Washington 98105, USA. Phone: (206) 987-2073; Fax: (206) 987-3890;

E-mail: jane.burns@seattlechildrens.org.

Conflict of interest: The authors have declared that no conflict of interest exists.

Nonstandard abbreviations used: cystic fibrosis (CF); Luria-Bertani (LB); minimal inhibitory concentration (MIC); deferrated casamino acid (DCAA); carbonyl cyanide $m$-chlorophenylhydrazone (CCCP); open reading frame (ORF); resistance/nodulation/cell division (RND); LysR-type transcriptional regulator (LTTR). individuals with CF. Intrinsic resistance to the aminoglycosides is related to lack of binding to lipopolysaccharide in the outer membrane (11). Resistance to the $\beta$-lactam antibiotics appears to be caused by synergistic mechanisms, including the induction of chromosomal $\beta$-lactamases $(12,13)$ and decreased drug access $(14,15)$. Other mechanisms of resistance may also be related to diminished antibiotic access (16), including drug efflux (17).

Antibiotic efflux is a common mechanism of antibiotic resistance in Gram-negative bacteria (18). Efflux pumps have been implicated in resistance to $\beta$-lactams, quinolones, tetracycline, chloramphenicol, trimethoprim, sulfamethoxazole, and aminoglycosides (19-26). The mechanism of antibiotic resistance appears to be a balance between entry by diffusion and active efflux; intracellular concentrations are kept low enough to be ineffectual at the target site (27). Efflux of other toxic compounds including dyes, detergents, and fatty acids by these pumps (18), as well as efflux of disinfectants such as triclosan (19), has also been described. There even appears to be a role for efflux systems in the tolerance of Pseudomonas aeruginosa to organic solvents (28).

We previously identified presumed efflux-mediated multidrug resistance in B. cenocepacia (29). OpcM, an outer membrane lipoprotein from a CF isolate of $B$. cenocepacia, was sequenced and characterized, demonstrating amino acid homology with OprM, the outer membrane component of an antibiotic efflux operon from $P$. aeruginosa. In addition, a DNA fragment upstream of $o p c M$ was partially sequenced and showed amino acid homology with MexB, the cytoplasmic membrane component of the $P$. aeruginosa operon. This 
suggested that a homologous antibiotic efflux operon might function in B. cepacia complex isolates. We have now isolated and sequenced the entire efflux gene cluster and have investigated the potential natural function of the efflux pump.

\section{Methods}

Strains and plasmids. Strains and plasmids used in these experiments are listed in Table 1 . Specific strains were selected for individual experiments, based on their phenotype (i.e., antibiotic susceptibility and salicylate production) and genetic features (i.e., ability to be transformed by electroporation and compatibility with specific plasmids), and both B. multivorans and $B$. cenocepacia strains were used, as well as Escherichia coli. Bacteria were stored at $-80^{\circ} \mathrm{C}$ in sterile skim milk and were freshly subcultured onto Luria-Bertani (LB) agar (30) with incubation for $24-48$ hours at $37^{\circ} \mathrm{C}$ prior to use. Broth cultures were also grown in LB (except where specified otherwise) at $37^{\circ} \mathrm{C}$ with shaking at $150 \mathrm{rpm}$. Antibiotics were added to culture media to maintain plasmids: tetracycline at $50 \mu \mathrm{g} / \mathrm{ml}$ for B. cepacia and $20 \mu \mathrm{g} / \mathrm{ml}$ for E. coli, and ampicillin at 100 $\mu \mathrm{g} / \mathrm{ml}$ for E. coli.

DNA preparation and analysis. Plasmid DNA was purified from E. coli and B. cepacia by an alkaline lysis technique followed by phenol-chloroform extraction for small-scale preparations (30) or resin purification (Qiagen, Valencia, California, USA) for large-scale preparations. Restriction endonucleases were used according to the instructions of the manufacturer (Invitrogen, Carlsbad, California, USA). DNA was analyzed by $0.7 \%$ agarose gel electrophoresis in Tris-borate buffer (30). Genomic DNA was harvested using the DNeasy Tissue Kit (Qiagen). Genetic transformation was performed by electroporation, but not all B. cenocepacia strains could be transformed; thus, the antibiotic-susceptible and readily transformable $B$. multivorans laboratory strain 249-2 was used as a host, as needed.

Nucleotide sequence analysis. DNA sequencing was performed at the University of Washington Department of Biochemistry Automated Sequencing Facility (Seattle, Washington, USA) using the ABI PRISM BigDye Terminator Cycle Sequencing Ready Reaction Kit (Applied Biosystems/Perkin Elmer, Foster City, California, USA). Because of the high $\mathrm{G}+\mathrm{C}$ content of $B$. cepacia $(67 \%)$, the standard protocol was modified by the addition of $1 \mu \mathrm{l} 100 \%$ DMSO to the reaction mixture.

Minimal inbibitory concentration determination. The minimal inhibitory concentrations (MICs) of chloramphenicol, trimethoprim, ciprofloxacin, ceftazidime, and gentamicin were determined by broth dilution technique, using National Committee on Clinical Laboratory Standards (31).

Reverse transcriptase-polymerase chain reaction (RT-PCR). RT-PCR was used for two purposes: for transcriptional analysis to determine if genes in the ceo cluster were cotranscribed, and for gene induction experiments to monitor gene expression. For analysis of cotranscrip- tion, RNA was extracted from mid-logarithmic phase bacteria using the GeneChoice RNA Spin Mini Kit (PGC Scientifics, Frederick, Maryland, USA). Extracted RNA was purified using the RNeasy Mini Kit (Qiagen) and was subjected to reverse transcription using the display THERMO-RT Kit (Display Systems, NeuroSearch, Copenhagen, Denmark) with primers for the ceo gene cluster listed in Table 2 . The resultant cDNA molecules were subjected to PCR using the GC-RICH PCR System (Roche Molecular Biochemicals, Indianapolis, Indiana, USA). Each PCR reaction also included amplification of cDNA synthesized as a control without reverse transcriptase to ensure that all amplifications were a result of cDNA and not contaminating DNA molecules.

For gene induction experiments, $B$. cenocepacia strain PC121 was grown to mid-logarithmic phase in LB broth in the presence of 0 or $10 \mathrm{mM}$ salicylate or 0,2 , or $5 \mu \mathrm{g} / \mathrm{ml}$ chloramphenicol. Total RNA was extracted by TriZol reagent (Molecular Research Center Inc., Cincinnati, Ohio, USA) and was subjected to reverse transcription using the OneStep RT-PCR Kit (Qiagen). Amplification of $r e c A$, a gene encoding a DNA-dependent ATPase, was used as a control. Two pairs of primers at final concentration of $10 \mu \mathrm{M}$ were used: the $c e o A$ forward and reverse primers (Table 2), and the recA forward and reverse primers BCR1 and BCR4 (32). The $c e o A$ primers generate a 1,195 -bp product from the ceo $A$ gene, while the recA primers generate a 527-bp product from the recA gene; the latter amplified product served as a loading control for all RT-PCR experiments. Reverse transcription and amplification were carried out as follows: (a) room temperature incubation at $50^{\circ} \mathrm{C}$ for 30 minutes; (b) initial PCR denaturation at

\section{Table 1}

Bacterial strains and plasmids

\begin{tabular}{|c|c|c|}
\hline & Description & $\begin{array}{l}\text { Source or } \\
\text { reference }\end{array}$ \\
\hline \multicolumn{3}{|l|}{ Strains } \\
\hline B. $c$ & $\begin{array}{l}\text { cenocepacia (genomovar III) CF isolate; } \\
\text { source of efflux gene cluster }\end{array}$ & $(12)$ \\
\hline B. mult & $\begin{array}{l}\text { Itivorans (genomovar II) laboratory isolate } \\
\text { does not encode ceoRllpEceoABopcM }\end{array}$ & $(12)$ \\
\hline PC121 & B. cenocepacia CF isolate $\quad \mathrm{P}$ & $\begin{array}{l}\text { Peter Gilligan } \\
\text { UNC }\end{array}$ \\
\hline CEP511 & B. cenocepacia CF isolate & $(22)$ \\
\hline GM2163 & E. coli dam- $\mathrm{dcm}^{-}$ & $\begin{array}{l}\text { New Englanc } \\
\text { BioLabs }\end{array}$ \\
\hline \multicolumn{3}{|l|}{ Plasmids } \\
\hline pLIN1 & $\begin{array}{l}\text { 23-kb insert from K61-3 in pVK102; } \\
\text { ceoRllpEceoABopcM }\end{array}$ & $(12)$ \\
\hline pSP329 & $7 \mathrm{~kb}, \mathrm{BHR}, \mathrm{p}_{t e t}, \mathrm{Tet}^{\mathrm{R}}$ & $(12)$ \\
\hline pAM1 & $\begin{array}{l}\text { 6.0-kb insert from K61-3 in pSP329; } \\
\text { ceoABopcM }\end{array}$ & This study \\
\hline pDN19lac $\Omega$ & 10.4 kb, Tet ${ }^{R}$, RK2 replicon & (16) \\
\hline pDN19lac 2 pceoR & $\begin{array}{l}1.2-\mathrm{kb} \text { insert from } \mathrm{K} 61-3 \\
\text { encoding the ceoR promoter } \\
\text { region in pDN/ac } \Omega\end{array}$ & This study \\
\hline
\end{tabular}

BHR, broad host range; Tet $^{R}$, tetracycline resistant; UNC, University of North Carolina (Chapel Hill, North Carolina, USA). 
Table 2

Primers used for PCR amplification

Primers for genes in the ceo gene cluster (size of amplified product)

CeoR (1.0 kb) Forward: 5'-GAGCACCGGCGCGCGTTCGGC-3'

Reverse: 5'-CCCACGAGGTAGCGCAGCCTTC-3'

LlpE (744 bp) Forward: 5'-CGCTGCCCGCGCAAGCCATAG-3'

Reverse: 5'-GTGGCGAGCGCGGCGTGCGTG-3'

$\operatorname{ceoA}(1.2 \mathrm{~kb}) \quad$ Forward: 5'-CCATCCTACGCACCTCCCGTTCC-3'

Reverse: 5'-CGCTTACGAATCCGCCTTCGCCG-3'

$c e o B(3.0 \mathrm{~kb}) \quad$ Forward: 5'-CGACCGGCCGATCTTTGCAGGAG-3'

$\operatorname{opcM}(1.5 \mathrm{~kb}) \quad$ Forward: 5'-CGCCGTCGGGTGCGTCGGCTTC-3'

Reverse: 5'-CGTCAGCCTTGCCAGACGCCGC-3'

Primers for $c e o R$ promoter region

ceoR promoter CeoKpn215: 5'-TCCGGTACCTTGGTGAAGCTGCTTGTATCG-3' region

$(1.2 \mathrm{~kb})$ CeoBam1366R: 5'-TACGGATCCGATTCGGGAACGGGAGGTG-3'
Reverse: 5'-GAACAGCGTCACGCCGAGCATCC-3'

methanol. A 10- $\mu$ l volume of the supernatant was spotted onto a silica $G$ thin-layer chromatography (TLC) plate; developed in chloroform, acetic acid, and ethanol (90:5:2.5); and visualized under UV light. B. multivorans strain 249-2 had previously been reported as not secreting salicylate (37) and was used as a negative control. In addition to the qualitative assay above, a quantitative TLC assay was developed in order to quantify intracellular drug. For this, the bacterial pellets resulting from centrifugation of cultures were resuspended in $50 \mu \mathrm{l}$ of phosphate-buffered saline and treated in a fashion similar to the treatment of the culture supernatants. After chromatography, the visualized spots migrating at the distance appropriate for salicylate were marked and the silica was scraped from the TLC plates and extracted with water for quantitation based on $\mathrm{OD}_{295}$ values, using a standard curve.

$95^{\circ} \mathrm{C}$ for 15 minutes; (c) $20-25$ cycles of denaturation at $95^{\circ} \mathrm{C}$ for 1 minute, annealing at $55^{\circ} \mathrm{C}$ for 1 minute, and polymerization at $72^{\circ} \mathrm{C}$ for 1 minute; and (d) final polymerization at $72^{\circ} \mathrm{C}$ for 10 minutes. The numbers of cycles of amplification (20 and 25) were selected to detect amplified products in the exponential phase. Samples were separated by electrophoresis on $1 \%$ agarose gels containing $0.5 \mu \mathrm{g} / \mathrm{ml}$ of ethidium bromide and were visualized under UV light.

Construction of lac Z fusions. The $1.2-\mathrm{kb}$ region upstream of $c e o R$, presumed to contain the $c e o R$ promoter, was amplified by PCR using primers CeoKpn215 and CeoBam1366R (Table 2). The PCR amplicon was cut with restriction enzymes $K p n I$ and BamHI, followed by fusion upstream of a promoterless $l a c Z$ in a vector, pDN19lac $\Omega$, that had been cut with KpnI/BamHI (33). The ligation product was transformed into competent E. coli GM2163 to obtain nonmethylated plasmid DNA, which was subsequently electroporated into $B$. cenocepacia strain PC121. This clone was subjected to $\beta$-galactosidase assays with the host strain containing only vector serving as a control for basal $\beta$-galactosidase activity.

$\beta$-galactosidase assays. As an indicator of $c e o R$ promoter activity, bacterial cells containing the $\mathrm{pDN} 19 \mathrm{lac} \Omega$ fusion were analyzed for $\beta$-galactosidase levels as described previously (34). Briefly, the bacterial cells were grown overnight in the presence or absence of potential inducers/suppressors including salicylate $(0,2,5$, and $10 \mathrm{mM}$ ) or chloramphenicol ( 0 and $5 \mu \mathrm{g} / \mathrm{ml})$ in Mueller Hinton broth and ferric chloride $(0-400 \mu \mathrm{M})$ in deferrated casamino acid (DCAA) media (35). The cells for the assay were harvested and the $\mathrm{OD}_{600}$ was adjusted to 0.6 in $\mathrm{Z}$ buffer before use in the assay.

Salicylate extraction assays. Bacteria were assayed for secreted and intracellular salicylate using the technique of Haas et al. (36). Briefly, bacteria were grown to mid-logarithmic phase in DCAA broth. Cells were pelleted by centrifugation and the supernatant was acidified, extracted twice with ethyl acetate, dried, and resuspended in
Efflux assays. The accumulation of radiolabeled chloramphenicol and salicylate was measured as described previously (38). Bacterial cells were grown to mid-logarithmic phase in LB broth. After the addition of $\left[{ }^{3} \mathrm{H}\right]$ chloramphenicol (or $\left[{ }^{14} \mathrm{C}\right]$ salicylate), the cells were incubated for 10 minutes at $37^{\circ} \mathrm{C}$, followed by the addition of $5 \mu \mathrm{M}$ of the proton conductor carbonyl cyanide $m$-chlorophenylhydrazone (CСCP), which deenergizes the bacterial cell membrane. Cells were sampled at 5-minute intervals and were centrifuged through silicon oil. The resulting cell pellets were assayed for incorporated radiolabel (i.e., intracellular drug) using scintillation spectrometry.

PCR amplification of genes from the ceo gene cluster. To determine the prevalence of the genes in the ceo operon, a panel of representative $B$. cepacia complex strains (39) was analyzed by PCR amplification of the individual genes comprising the ceo operon. Genomic DNA was subjected to PCR amplification for the five ceo genes using primers listed in Table 2 and the GC-RICH PCR System. The samples were subjected to an initial denaturation at $95^{\circ} \mathrm{C}$ for 4 minutes, followed by ten cycles of denaturation $\left(95^{\circ} \mathrm{C}\right.$ for 30 seconds), annealing $\left[66^{\circ}-70^{\circ} \mathrm{C}\right.$ (depending on the primer pair) for $30 \mathrm{sec}-$ onds] and elongation $\left[72^{\circ} \mathrm{C}\right.$ for $1-3$ minutes (depending on the length of the product expected)]. The next 20 cycles increased the time of elongation by 5 seconds for each successive cycle. After a final elongation at $72^{\circ} \mathrm{C}$ for 7 minutes, the samples were stored at $4^{\circ} \mathrm{C}$ until they were used for electrophoresis.

\section{Results}

Nucleotide sequence analysis. Sequencing the entire 23-kb insert in pLIN1 and subjecting the sequence to a BLASTx search (40) revealed only six open reading frames (ORFs) of interest. Five were clustered and showed homology to a regulator, a lipase-like component, and three components of multidrug efflux systems (including opcM and two additional genes). The 
sixth ORF, which is $4 \mathrm{~kb}$ downstream of opcM, showed $37 \%$ identity to a B. cepacia phthalate transporter gene. Only the five clustered genes were investigated further at this time. The ORFs encoding the two other components of a putative multidrug efflux system were upstream of $о p c M(29)$ and in the same reading frame and orientation. Upstream of the efflux genes were two additional ORFs: one in the same orientation (llpE), and the other immediately upstream and in the opposite orientation $(c e o R)$. This genomic region, consisting of ceoR, $l p$ E $, c e o A, c e o B$, and $o p c M$, has been called "ceo," for cepacia efflux operon. The details of a pBLAST search of these five ORFs are listed in Table 3.

The genes $c e o A, c e o B$, and $o p c M$ appear to comprise structural genes with significant homologies to the resistance/nodulation/cell division (RND) family of proteins, several members of which are components of multidrug efflux systems. A BLAST protein search of CeoA revealed the highest degree of homology (41\% identical and $55 \%$ similar) was to MexE, the periplasmic link protein encoded by the mexEF/oprN antibiotic efflux operon from $P$. aeruginosa (20). This operon confers resistance to tetracycline, ciprofloxacin, and the $\beta$-lactams. A pairwise alignment of CeoA and MexE revealed a 60 -amino-acid stretch of high homology, suggesting that the conserved residues may play an essential functional or structural role. A BLAST search of the predicted amino acid sequence of $\mathrm{CeoB}$ revealed the highest degree of homology was to $\mathrm{MexF}$ (59\% identity and 73\% similarity), the cytoplasmic membrane component of the MexEF/OprN pump (20). There are four highly conserved motifs characterizing both proteins. Subjecting CeoB to topological analysis (41) predicted 12 transmembrane helices with two large external loops between transmembrane strands 1 and 2 and transmembrane strands 7 and 8 . Comparative sequence analysis of $\mathrm{CeoB}$ revealed similarity between the $\mathrm{N}$ - and C-terminal halves of the protein, with six transmembrane helices in each half, implying evolution via intragenic duplication of an ancestral protein with six transmembrane helices (41). The GenBank accession number for $c e o A B$ is U97042. An analysis of OpcM, an outer membrane lipoprotein homologous with the outer membrane component of several $P$. aeruginosa efflux pumps, has already been reported (29).

Two additional genes were identified in the gene cluster. The first of these, $c e o R$, is probably a regulator. A BLAST search of predicted amino acid sequence revealed homology to several members of the LysR-type transcriptional regulator (LTTR) family. The reading frame of $c e o R$ has an orientation opposite to that of the putative structural genes, a feature shared with the majority of LTTR members (42). The second ORF in the ceo operon $l p E$ (lipase-like protein for efflux) shows moderate protein homology to various esterases and lipases, both prokaryotic and eukaryotic, most of which belong to the "GDXG" family of lipolytic enzymes. Some of the functions of the homologs include removal of the $N$-acetyl group from the antibiotic bialaphos (Bah protein from Streptomyces hygroscopicus) (43) and hydrolysis of $p$-nitrophenyl butyrate (mammalian hormone sensitive lipase) (44). LlpE is not related to previously characterized B. cepacia lipases, which hydrolyze lipid substrates and are not associated with antibiotic resistance $(45,46)$. The PSORT program, which predicts protein localization sites (47), classified LlpE as a putative periplasmic or outer membrane protein, based on the presence of a signal sequence in the first 22 amino acids (48). The GenBank accession number for ceoRllpE is AY008288.

Transcriptional analysis using RT-PCR. We prepared cDNA from RNA isolated from B. cenocepacia strain K61-3 and amplified it by PCR using primer pairs that would allow detection of cotranscription (Figure 1). The cDNA synthesized using a primer that annealed to $o p c M$ was amplified by PCR using primers internal to $c e o B$ and $o p c M$, and the resulting $0.77-\mathrm{kb}$ band indicated cotranscription of $o p c M$ and $c e o B$. Similarly, a $1.35-\mathrm{kb}$ band from $c e o A B$ was amplified using $c e o B$-primed cDNA and primers from $c e o A$ and $c e o B$, and a $0.63-\mathrm{kb}$ band from $l l p E$ was amplified using $c e o A$-primed cDNA and primers internal to $l l p E$; this suggested cotranscription of $c e o B$ with $c e o A$, and $c e o A$ with $l_{p} E$, respectively.

Antibiotic susceptibility. Antibiotic susceptibility was tested in an antibiotic-susceptible B. cenocepacia clinical isolate that could be readily transformed, CEP511 (39). A 6-kb fragment of DNA from the wild-type strain

\section{Table 3}

Nucleotide sequence analysis

\begin{tabular}{|c|c|c|c|c|}
\hline Name of ORF & $\begin{array}{l}\text { Size (no. of } \\
\text { nucleotides) }\end{array}$ & Proposed function & Homologies & Unique features \\
\hline$c e o R$ & 1,014 & Regulator & LTTR & $\begin{array}{c}\text { Divergently transcribed from } \| / p E c e o A c e o B o p c M \\
\text { predicted protein mol wt, } 11,000\end{array}$ \\
\hline$\| p E$ & 714 & Unknown & $\begin{array}{l}\text { GDXG family of } \\
\text { lipolytic enzymes }\end{array}$ & $\begin{array}{l}\text { Putative periplasmic/outer membrane protein } \\
\text { predicted mature protein mol wt, } 28,495\end{array}$ \\
\hline $\operatorname{ceo} A$ & 1,218 & $\begin{array}{l}\text { Periplasmic link protein } \\
\text { involved in drug efflux }\end{array}$ & $\operatorname{mex} A, \operatorname{mex} C, \operatorname{mex} E, a c r A$ & $\begin{array}{c}\mathrm{N} \text {-terminal signal sequence; } \\
\text { predicted mature protein mol wt, 40,817 }\end{array}$ \\
\hline$c e o B$ & 3,083 & $\begin{array}{l}\text { Cytoplasmic membrane component } \\
\text { of drug efflux pump }\end{array}$ & $\operatorname{mex} B, \operatorname{mex} D, \operatorname{mex} F, a c r B$ & $\begin{array}{l}\text { Cytoplasmic membrane protein } \\
\text { of predicted mol wt } 110,945\end{array}$ \\
\hline opcM & 1,536 & $\begin{array}{l}\text { Outer membrane component } \\
\text { of drug efflux pump }\end{array}$ & oprM, oprN, oprJ & Previously reported (29) \\
\hline
\end{tabular}




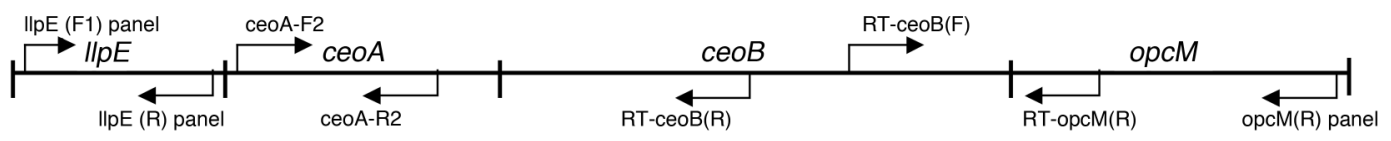

\begin{tabular}{|c|c|c|c|c|c|c|c|c|c|c|c|}
\hline Lane & $\begin{array}{c}\text { Genes } \\
\text { amplified }\end{array}$ & $\begin{array}{c}\text { Primer for } \\
\text { template cDNA }\end{array}$ & Primers for $\mathrm{PCR}$ & $\begin{array}{c}\text { Expected } \\
\text { band size }(\mathrm{kb})\end{array}$ & $=$ & A & B & C & $D$ & $=$ & \\
\hline A & None ${ }^{*}$ & ceoA-R2 & $\begin{array}{l}\text { IlpE (F1) panel } \\
\text { IlpE }(\mathrm{R}) \text { panel }\end{array}$ & None & & & & & & $=$ & 10.0 \\
\hline B & $\begin{array}{l}\| p E / \\
c e O A\end{array}$ & ceoA-R2 & $\begin{array}{l}\text { IlpE }(\mathrm{F} 1) \text { panel } \\
\text { IlpE }(\mathrm{R}) \text { panel }\end{array}$ & 0.63 & $\underline{-}$ & & & & & 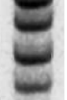 & \\
\hline $\mathrm{C}$ & $\begin{array}{l}\text { ceoAl } \\
c e o B\end{array}$ & RT-ceoB (R) & $\begin{array}{c}\text { coeA-F2 } \\
\mathrm{RT}-\operatorname{ceoB}(\mathrm{R})\end{array}$ & 1.35 & - & s & & & & - & $\begin{array}{l}2.0 \\
1.5\end{array}$ \\
\hline $\mathrm{D}$ & $\begin{array}{l}\text { ceoB/ } \\
\text { opcM }\end{array}$ & $\begin{array}{l}\text { opcM }(R) \\
\text { panel }\end{array}$ & $\begin{array}{l}\text { RT-ceoB (F) } \\
\text { RT-opcM (R) }\end{array}$ & 0.77 & $=$ & & $\frac{7}{4}$ & I & - & $=$ & $\begin{array}{l}1.0 \\
0.8 \\
0.6\end{array}$ \\
\hline
\end{tabular}

\section{Figure 1}

The ceo operon was analyzed by RT-PCR to assess cotranscription of $I p E, c e o A, c e o B$, and opcM. The order of the structural genes of the ceo operon as well as the positioning of the primers used in CDNA synthesis and in PCR amplification are shown on top. Each PCR amplification also included amplification of CDNA synthesized as a control without reverse transcriptase to ensure that all amplification was a result of cDNA and not contaminating DNA molecules; a representative result is shown in lane $\mathrm{A}$. Lanes $\mathrm{B}, \mathrm{C}$, and $\mathrm{D}$ show amplification of $I / p E, c e o A$, and $c e o B$, respectively. The appearance of expected bands in the three sets of PCR reactions impies cotranscription of $l p E, c e o A, c e o B$, and opcM. ${ }^{*} \mathrm{No}$ reverse transcriptase; this experiment was performed for all reactions and was negative, but data are shown only for the llpE reaction.

K61-3 was cloned into the broad host range vector pSP329, with selection for chloramphenicol resistance. The resulting construct, pAM1, had the three putative pump structural genes (ceoABopcM) expressed under the control of a tet promoter. The results of MIC determinations for strain CEP511 with pAM1 are listed in Table 4 . A decrease of approximate 10 -fold in susceptibility to chloramphenicol, trimethoprim, and ciprofloxacin, but not ceftazidime or gentamicin, was demonstrated compared with CEP511 containing vector alone. Because of the availability of radiolabeled drug, chloramphenicol was selected as the prototype antibiotic for subsequent studies.

Salicylate secretion. Because of previous reports of salicylate-inducible multiple antibiotic resistance in $B$. cepacia complex (37), a link between salicylate secretion and antibiotic resistance was sought. Qualitative assays of salicylate concentration demonstrated no detectable secretion of the siderophore into culture supernatant by strain 249-2, compared with easy detection in the strain 249-2(pAM1), which contains сеоABopcM. However, quantitative analysis of bacterial pellets detected similar amounts of intracellular salicylate in strain 249-2 and in strain 249-2(pAM1), containing the structural genes for the putative efflux operon (12.9 vs. $13.6 \mu \mathrm{g} / \mathrm{ml}$, respectively). These results suggested that strain 249-2 can synthesize but not secrete salicylate. Specific drug efflux experiments were subsequently performed to investigate the role of the ceo gene cluster in salicylate efflux.
Drug efflux. To address whether the genes in the operon encoded an energy-dependent antibiotic efflux pump, strain 249-2(pSP329), a control including the vector alone, and strain 249-2(pAM1) were assayed for efflux of $\left[{ }^{3} \mathrm{H}\right]$ chloramphenicol before and after the addition of the proton conductor CCCP. Strain 249-2(pAM1) demonstrated significantly less cell-associated chloramphenicol at baseline with an increase to level similar to that of 249-2(pSP329), after the proton motive force was disrupted by CCCP (Figure 2a). The amount of cell-associated chloramphenicol reproducibly decreased in strain 249-2(pSP329) after the addition of CCCP. Quantitative cultures demonstrated a decrease in viable 249-2(pSP329) cells after the addition of CCCP. The viability of 249-2(pAM1) appeared to be unaffected by CCCP, suggesting a possible role in the efflux of this compound, as well. The possibility of nonspecific efflux of radiolabeled drug was ruled out by measurement of the accumulation of $\left[{ }^{3} \mathrm{H}\right]$ benzyl penicillin, which did not fluctuate with the addition of CCCP (data not shown).

\section{Table 4}

Minimal inhibitory concentrations $(\mu \mathrm{g} / \mathrm{ml})$

\begin{tabular}{lccccc}
\hline & \multicolumn{5}{c}{ Antibiotics } \\
Strain & Cm & Tmp & Cip & Gent & Ctz \\
CEP511 (pSP329) & 12.5 & 0.39 & 25 & $>200$ & 1.56 \\
CEP511 (pAM1) & 100 & 3.15 & 200 & $>200$ & 1.56 \\
\hline
\end{tabular}

Cm, chloramphenicol; Tmp, trimethoprim; Cip, ciprofloxacin; Gent, gentamicin; Ctz, ceftazidime. 


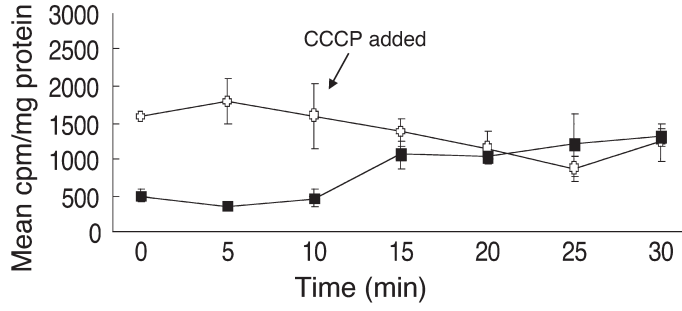

b

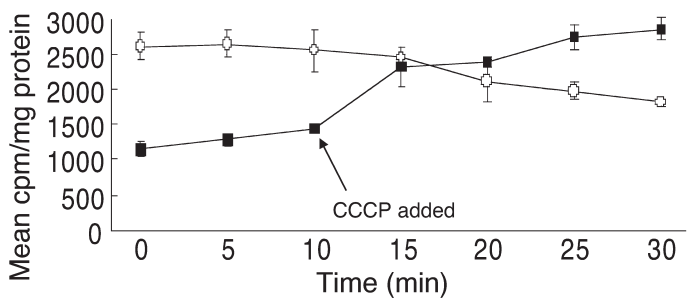

Figure 2

Drug accumulation in isogenic strains with and without the efflux gene cluster. Energy-dependent efflux of $\left[{ }^{3} \mathrm{H}\right]$ chloramphenicol $(\mathbf{a})$ and $\left[{ }^{14} \mathrm{C}\right]$ salicylate (b) by B. cepacia. Strains 249-2(pAM1) (filled squares) and 249-2(pSP329) (open circles) were assayed for accumulation of radiolabel before and after the addition of $250 \mu \mathrm{M}$ CCCP. The addition of CCCP increased cell-associated accumulation of both drugs (i.e., decreased drug efflux) in 249-2(pAM1). Data points represent the means of three experiments with error bars showing the SD.

Because previous studies had demonstrated that salicylate, the most commonly produced siderophore in B. cepacia complex isolates from patients with CF (49), could induce multiple antibiotic resistance (37), studies were performed to determine whether there was an association between the efflux of chloramphenicol and salicylate. As noted above, strain 249-2, previously reported to be a strain that did not produce salicylate, appeared to be able to synthesize but not excrete salicylate. Strains 249-2(pAM1) and 249-2(pSP329) were again compared, this time for their ability to actively efflux $\left[{ }^{14} \mathrm{C}\right]$ salicylate (Figure $2 \mathrm{~b}$ ). After the addition of CCCP, levels of cell-associated salicylate decreased, as for chloramphenicol in the vector-only construct, whereas 249-2(pAM1) showed a significant increase in cell-associated $\left[{ }^{14} \mathrm{C}\right]$ salicylate, suggesting the ceo pump is able to efflux salicylate.

\section{Figure 3}

Effect of growth conditions on $c e o R$ promoter activity. Effects of the concentrations of iron (a), salicylate (b), and chloramphenicol (c) on $c e o R$ promoter-driven expression of $\beta$-galactosidase using a ceo $R$ lacZ fusion, pDN19lac $\Omega p c e o R$ (black bars), compared with $\mathrm{pDN} 19$ lac $\Omega$ without the $c e o R$ promoter region (gray bars). The host strain was PC121, which secretes salicylate in response to iron starvation and demonstrates salicylate-inducible resistance to chloramphenicol, trimethoprim, and ciprofloxacin. For the iron titration, it was necessary to perform the experiment on 3 different days; thus, the data were normalized for comparison. The salicylate and chloramphenicol experiments were performed in triplicate on the same day, thus normalization was not required. Each data point shows the mean and SD.
Induction of the ceo operon by salicylate and chlorampheni$\mathrm{col}$. Two sets of experiments were performed to examine the possibility of induction of the ceo operon. The first of these investigated the regulation of $c e o R$. The putative $c e o R$ promoter region was fused upstream of the promoterless lac $Z$ in the broad host range vector $\mathrm{pDN} 19 \mathrm{lac} \Omega$ (16), and the construct was introduced into strain PC121. PC121 is a B. cenocepacia clinical isolate that demonstrates salicylate production and antibiotic resistance induced by low iron concentrations, rather than constitutively, as seen in the wild-type strain K61-3. The resultant strain, PC121(pDN19lac ppceoR), was grown overnight in media with variable concentrations of ferric chloride, salicylate, or chloramphenicol. A linear decrease in $\beta$-galactosidase activity was demonstrated with increasing iron concentration (Figure 3a), indicating a decrease in $c e o R$ promoter activity. In the presence of exogenous salicylate $(10 \mathrm{mM})$, increased $c e o R$ promoter activity was shown (Figure $3 b$ ). With the addition of concentrations of chloramphenicol below the MIC (2 and $5 \mu \mathrm{g} / \mathrm{ml}$ ), promoter activity also increased (Figure 3c). These results suggest upregulation of the ceo $R$ promoter by low concentrations of iron (via salicylate) and by concentrations of chloramphenicol that are below the MIC.

In order to determine the association between regulation of $c e o R$ and production of the efflux pump, RTPCR was used to examine salicylate and chloramphenicol induction of $c e o A$. The results of these RT-PCR experiments demonstrated that $10 \mathrm{mM}$ salicylate upregulated ceoA (Figure 4a), as did increasing concentrations of chloramphenicol (Figure 4b).

Phenotypic correlation with ceo efflux genes in B. cepacia complex strains. The prevalence of the ceo gene cluster was examined in 31 strains representing clinical (CF and
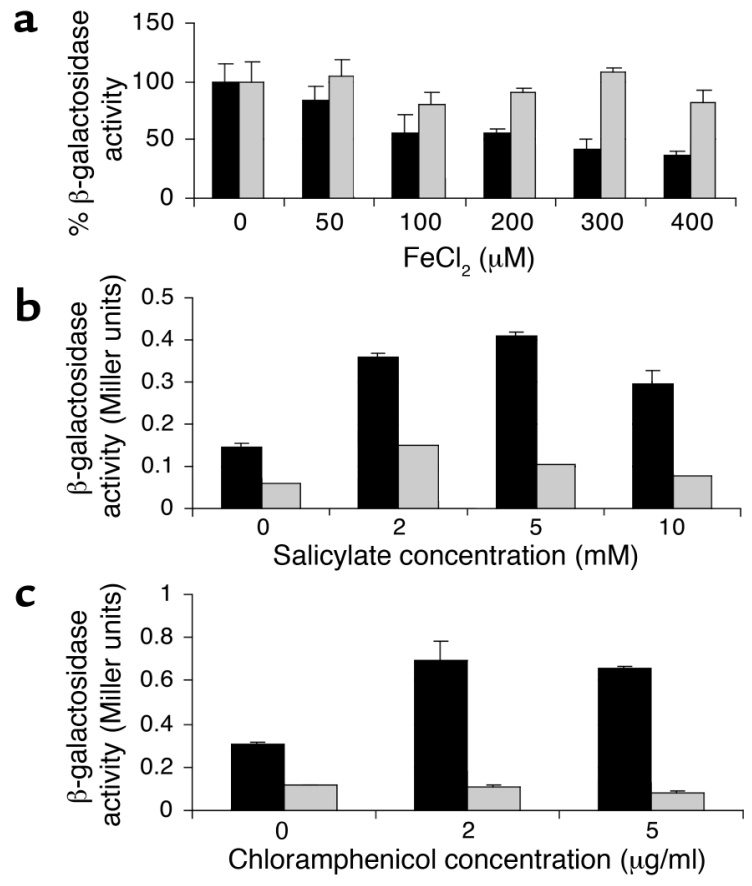


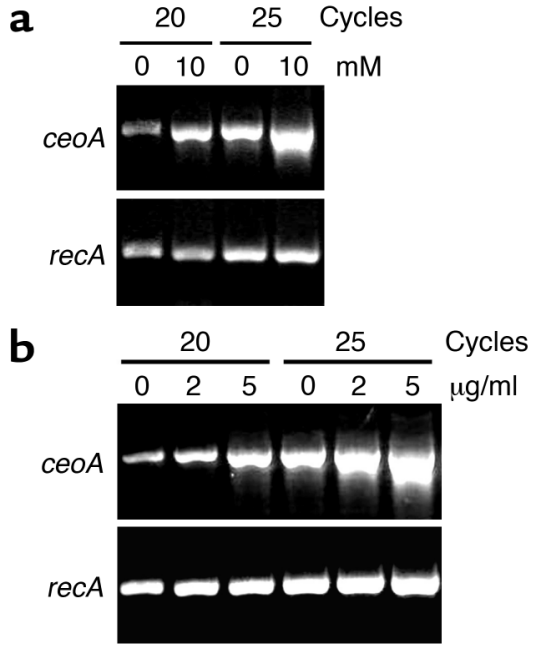

Figure 4

Effect of growth conditions on gene induction. RT-PCR amplification of ceoA following induction with salicylate (a) and chloramphenicol (b). This experiment was performed in B. cenocepacia strain PC121, which demonstrates inducible salicylate secretion. Concentrations of salicylate and chloramphenicol were 0 and $10 \mathrm{mM}$, and 0,2 , and $5 \mu \mathrm{g} / \mathrm{ml}$, respectively.

non-CF) and environmental isolates from five of the most common genomovars of B. cepacia complex (39). Only B. cenocepacia isolates contained all of the components identified in the ceo gene cluster (Table 5). Within the group of ten B. cenocepacia isolates that were tested, five amplified all five components of the operon. Two genes, $c e o R$ and $c e o B$, were amplified from all ten isolates, including the non-CF clinical isolate, FC663. Interestingly, ceo $R$ was amplified only from $B$. cenocepacia. None of the genes in the cluster were detected within the four B. vietnamiensis (genomovar V) strains tested. Within the other three genomovars tested, $c e o A$ and $c e o B$ were amplified in 15 of 17 and 11 of 17 isolates, respectively.

Susceptibility to chloramphenicol, trimethoprim, and ciprofloxacin as well as secretion of salicylate were examined within the group of ten $B$. cenocepacia isolates (Table 6). Resistance to all three agents was identified in four of the five isolates in which the entire operon was present. However, in PC121, a clinical isolate with the entire operon but in which salicylate secretion was inducible rather than constitutive, antibiotic susceptibility was demonstrated. In the other five isolates that did not contain all five genes from the cluster, there was not a single strain that not only was resistant to all three antibiotics but also secreted salicylate. The fact that some of the isolates that did not contain the entire operon were nonetheless resistant to some antibiotics is not surprising, given the many potential alternate mechanisms of resistance, including decreased diffusion through porins and alternative efflux pumps (14, 50). Salicylate secretion has not been studied as well as antibiotic resistance. However, in addition to the six $B$. cenocepacia $\mathrm{CF}$ isolates that secreted salicylate, there was one B. multivorans isolate from a CF patient that also secreted salicylate and was fully susceptible to chloramphenicol, trimethoprim, and ciprofloxacin, despite the absence of all but one gene in the operon $(c e o A)$. This suggests that in this isolate, an alternative mechanism for salicylate secretion not linked to antibiotic efflux is functioning.

Induction of resistance by passage on mucin-containing agar. In an attempt to partially emulate the conditions present in CF sputum, a clinical isolate of $B$. cenocepacia obtained from the bronchoalveolar lavage fluid of a 1-year-old child with CF was passaged 25 times on Mueller Hinton agar containing 10 grams per $100 \mathrm{ml}$ porcine gastric mucin. At baseline, the organism was susceptible to chloramphenicol (MIC $=4 \mu \mathrm{g} / \mathrm{ml}$ ). However, after 25 passages and without exposure to antibiotics, the MIC of chloramphenicol increased to $50 \mu \mathrm{g} / \mathrm{ml}$. PCR amplification demonstrated presence of all components of the ceo operon in this isolate.

\section{Discussion}

Antibiotic resistance in B. cenocepacia is of the utmost importance, because of both the organism's transmissibility and its virulence in CF. The identification of efflux pumps in B. cepacia complex is not unexpected (50). These nutritionally versatile organisms, which have been used for bioremediation (51-53), have also been implicated in multiple nosocomial outbreaks as a result of resistance to common hospital disinfectants $(54,55)$.

Screening of a cosmid library constructed from a CF clinical isolate for chloramphenicol resistance allowed the identification of the first antibiotic efflux operon to our knowledge in B. cepacia complex. Five components of a gene cluster have been identified. Oriented in one direction and likely comprising a single transcript are genes encoding a putative periplasmic lipaselike protein $(l l p E)$, a putative periplasmic linker $(c e o A)$, a putative cytoplasmic membrane component (ceoB), and an outer membrane protein $(o p c M)(29)$. Upstream of the four structural genes and oriented in the opposite direction is a sequence encoding a putative LTTR $(c e o R)$. Transfer of a cosmid clone containing all five components of the ceo gene cluster into an antibioticsusceptible $B$. multivorans laboratory strain also transferred resistance to chloramphenicol, trimethoprim, and ciprofloxacin, but not resistance to the aminoglycosides or $\beta$-lactam antibiotics (16).

Each ORF was evaluated separately as a potential component of an antibiotic efflux operon. CeoA, CeoB, and OpcM all have homologs in P. aeruginosa and other Gram-negative RND-type efflux pumps. The strongest homologies for $c e o A B o p c M$ were seen with the $P$. aeruginosa RND pump mexEFoprN, which confers resistance to chloramphenicol, tetracycline, quinolones, and imipenem (20). That pump is also positively regulated by an LTTR, MexT (56). Subjecting CeoA, CeoB, and OpcM to pairwise alignments with their $P$. aeruginosa counterparts revealed certain amino acid stretches of high homology; these may help to identify conserved residues that play essential functional or structural 
Table 5

Presence of ceo gene cluster in five genomovars tested

\begin{tabular}{|c|c|c|c|c|c|c|}
\hline \multirow[b]{2}{*}{ Strain } & \multirow[b]{2}{*}{ Source } & \multicolumn{5}{|c|}{ Presence of ceo gene cluster } \\
\hline & & $c e o R$ & $I I p E$ & ceoA & $c e o B$ & $o p c N$ \\
\hline \multicolumn{7}{|c|}{ B. cepacia (genomovar I) } \\
\hline CEP 31 & Onion & - & - & + & + & - \\
\hline CEP 80 & Environment & - & - & + & + & - \\
\hline FC 461 & Non-CF & - & - & + & + & - \\
\hline CEP 509 & $\mathrm{CF}$ & - & - & + & + & - \\
\hline \multicolumn{7}{|c|}{ B. multivorans (genomovar II) } \\
\hline $249-2$ & Lab & - & - & - & - & - \\
\hline CEP 144 & Environment & - & - & - & + & + \\
\hline FC 147 & Non-CF & - & - & + & - & - \\
\hline FC 445 & CF & - & - & + & - & - \\
\hline FC 461 & $\mathrm{CF}$ & - & - & + & + & - \\
\hline FC 762 & Non-CF & - & - & + & - & - \\
\hline FC 769 & CF & - & - & + & + & - \\
\hline CEP 781 & CF & - & - & + & + & - \\
\hline CEP 5393 & $\mathrm{CF}$ & - & - & + & - & - \\
\hline \multicolumn{7}{|c|}{ B. cenocepacia (genomovar III) } \\
\hline CEP 24 & CF & + & - & + & + & + \\
\hline CEP 138 & CF & + & + & - & + & - \\
\hline CEP 238 & $\mathrm{CF}$ & + & - & - & + & - \\
\hline FC 475 & $\mathrm{CF}$ & + & + & + & + & + \\
\hline FC 505 & $\mathrm{CF}$ & + & + & + & + & + \\
\hline CEP 511 & $\mathrm{CF}$ & + & - & - & + & - \\
\hline CEP 565 & $\mathrm{CF}$ & + & + & + & + & + \\
\hline CEP 5424 & $\mathrm{CF}$ & + & + & + & + & + \\
\hline PC 121 & $\mathrm{CF}$ & + & + & + & + & + \\
\hline FC 663 & Non-CF & + & - & - & + & - \\
\hline \multicolumn{7}{|c|}{ B. stabilis (genomovar IV) } \\
\hline FC 367 & $\mathrm{CF}$ & - & - & + & + & - \\
\hline FC 472 & Environment & - & - & + & + & - \\
\hline FC 779 & Non-CF & - & - & + & + & - \\
\hline CEP 7322 & $\mathrm{CF}$ & - & - & + & - & - \\
\hline \multicolumn{7}{|c|}{ B. vietnamiensis (genomovar $\mathrm{V}$ ) } \\
\hline CEP 40 & $\mathrm{CF}$ & - & - & - & - & - \\
\hline FC 369 & Environment & - & - & - & - & - \\
\hline FC 441 & Non-CF & - & - & - & - & - \\
\hline FC 466 & CF & - & - & - & - & - \\
\hline
\end{tabular}

-, absent; +, present.

roles in the efflux of common substrates for the CeoAB/OpcM and MexEF/OprN systems.

A significant difference from other prokaryotic multidrug efflux systems, including all RND pumps described to date, is the inclusion of a gene encoding a lipase-like protein (LlpE) in the B. cenocepacia efflux operon. Based on both its conservation in the majority of strains containing ceoABopcM and the fact that it is apparently cotranscribed with those structural efflux genes, $l_{p} E$ would appear to be an integral part of the operon. However, both efflux and similar levels of antibiotic resistance were mediated by constructs with just ceoABopcM (pAM1) and those containing the entire gene cluster (pLIN1). Amino acid homologies suggest a possible role for $\mathrm{LlpE}$ in the hydrolysis or binding of one or more antibiotics. This is an attractive idea, given that the mammalian hormone-sensitive lipase has been shown to hydrolyze $p$-nitrophenyl butyrate (44), which is structurally similar to chloramphenicol. Experiments are ongoing in our laboratory to elucidate the function of LlpE.

The energy-dependent transport of both chloramphenicol and salicylate by this efflux system suggests that perhaps in nature salicylate is the true substrate for the pump. However, as with the majority of functions in B. cepacia complex isolates, all of which contain multiple chromosomes, there appears to be redundancy in salicylate efflux. B. cenocepacia strains that contain only two or three genes from the ceo cluster, as well as strains from other genomovars, are able to secrete salicylate, so it is unlikely that the ceo efflux pump is the only mechanism for secreting this important siderophore.

In addition to its role as a siderophore, salicylate is an important exoproduct of $B$. cepacia complex strains that is used as a signal molecule in plant pathogenesis (57, 58). Of note, salicylate is the most commonly identified siderophore in CF isolates of B. cepacia complex (49). Because iron scavenging is such an important step in bacterial pathogenesis, the secretion of salicylate in the CF lung, which has inherently low iron concentrations (36), is critical. While this is the first proposed natural substrate to our knowledge for an RND-type efflux pump, Furrer et al. (59) have reported the secretion of enterobactin, a siderophore in E. coli, via p43, an integral membrane protein homologous to the major facilitator superfamily of export pumps, suggesting that this may be a common theme.

The link between the efflux of antibiotics and salicylate assumes increased clinical relevance, because we have demonstrated that salicylate induces antibiotic resistance in B. cenocepacia isolates. A model suggested by these data is that $\mathrm{Ceo} \mathrm{R}$ is a salicylate-regulated transcriptional activator for $l l p E c e o A B o p c M$, much like NahR, an LTTR from $P$. putida that uses salicylate as a coinducer (42). Interestingly, MexT, the

\section{Table 6}

Correlation of ceo operon, salicylate secretion and resistance in $B$. cenocepacia isolates

\begin{tabular}{lccccc}
\hline & Genes & Salicylate & \multicolumn{3}{c}{ MIC $(\mu \mathrm{g} / \mathrm{ml})$} \\
& present & secretion & $\mathrm{Cm}^{\mathrm{A}}$ & $\mathrm{Tmp}^{\mathrm{B}}$ & $\mathrm{Cip}^{\mathrm{C}}$ \\
K61-3 & 5 & Yes & $>200$ & 32 & 16 \\
CEP 565 & 5 & Yes & 64 & $>32$ & 4 \\
FC 475 & 5 & Yes & 32 & $>32$ & 16 \\
FC 505 & 5 & Yes & 32 & 16 & $>32$ \\
CEP 5424 & 5 & Yes & 64 & $>32$ & 4 \\
PC 121 & 5 & Yes $^{\text {D }}$ & 8 & $\leq 1$ & 0.5 \\
CEP 24 & 4 & No & 64 & $>32$ & 16 \\
CEP 138 & 3 & Yes & 16 & $>32$ & 4 \\
CEP 511 & 2 & No & 8 & 2 & 16 \\
CEP 238 & 2 & Yes & 64 & 8 & 4 \\
FC 663 & 2 & No & 8 & $\leq 1$ & 1
\end{tabular}

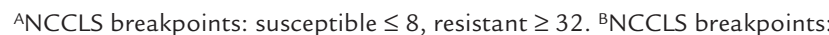
susceptible $\leq 4$, resistant $\geq 16$. CNCCLS breakpoints: susceptible $\leq 1$, resistant $\geq 4$. DSalicylate secretion by PC121 is inducible, not constitutive, as was found in the other B. cenocepacia isolates examined. NCCLS, National Committee on Clinical Laboratory Standards. 
LTTR from $P$. aeruginosa that is a transcriptional activator for mexEFoprN, while homologous with NahR, does not use salicylate as a coinducer (56). Because salicylate does not function as a siderophore in $P$. aeruginosa, this is not surprising.

B. cepacia complex is often described as the most resistant of the CF pulmonary pathogens, and a link with iron limitation, via the salicylate pathway, suggests the need for further investigation of this potential regulatory pathway. Our findings suggest that maintenance of an efflux pump by B. cepacia may contribute to its virulence both in human disease and, potentially, in its role in the environment. If salicylate is the natural substrate for this efflux pump and the pump is regulated by low iron concentrations, this would imply that the milieu of the CF lung would be sufficient to induce antibiotic resistance in isolates of $B$. cepacia complex, even without the selective pressure of antibiotics.

\section{Acknowledgments}

This work was funded by grants from the NIH (AI23975), the CF Foundation (BURNS00P0), and the University of Washington Royalty Research Fund. We would like to thank Craig Pritzlaff, Rebecca Charron, John Barry, and Amy Lee for technical assistance.

1. Cystic Fibrosis Foundation. 2003. Patient Registry 2002 Annual Data Report. Bethesda, Maryland, USA.

2. Thomassen, M.J., Demko, C.A., Klinger, J.D., and Stern, R.C. 1985. Pseudomonas cepacia colonization among patients with cystic fibrosis. Am. Rev. Respir. Dis. 131:791-796.

3. LiPuma, J.J., et al. 2001. Disproportionate distribution of Burkholderia cepacia complex species and transmissibility markers in cystic fibrosis. Am. J. Respir. Crit. Care Med. 164:92-96.

4. Mahenthiralingam, E., Baldwin, A., and Vandamme, P. 2002. Burkbolderia cepacia complex infection in patients with cystic fibrosis. J. Med. Microbiol. 51:533-538.

5. Vandamme, P., et al. 2003. Burkholderia cenocepacia sp. nov.-a new twist to an old story. Res. Microbiol. 154:91-96.

6. Coenye, T., Vandamme, P., Govan, J.R., and LiPuma, J.J. 2001. Taxonomy and identification of the Burkholderia cepacia complex. J. Clin. Microbiol. 39:3427-3436.

7. Mahenthiralingam, E., et al. 2001. Infection with Burkbolderia cepacia complex genomovars in patients with cystic fibrosis: virulent transmissible strains of genomovar III can replace Burkholderia multivorans. Clin. Infect. Dis. 33:1469-1475.

8. Bernhardt, S.A., Spilker, T., Coffey, T., and LiPuma, J. 2003. Burkholderia cepacia complex in cystic fibrosis: frequency of strain replacement during chronic infection. Clin. Infect. Dis. 37:780-785.

9. LiPuma, J.J., et al. 2001. Disproportionate distribution of Burkholderia cepacia complex species and transmissibility markers in cystic fibrosis. Am. J. Respir. Crit. Care Med. 164:92-96.

10. Speert, D.P., Henry, D., Vandamme, P., Corey, M., and Mahenthiralingam, E. 2002. Epidemiology of Burkholderia cepacia complex in patients with cystic fibrosis, Canada. Emerg. Infect. Dis. 8:181-187.

11. Moore, R.A., and Hancock, R.E.W. 1986. Involvement of outer membrane of Pseudomonas cepacia in aminoglycoside and polymyxin resistance. Antimicrob. Agents Chemother. 30:923-926.

12. Prince, A., Wood, M.S., Cacalano, G.S., and Chin, N.X. 1988. Isolation and characterization of a penicillinase from Pseudomonas cepacia 249. Antimicrob. Agents Chemother. 32:838-843.

13. Trepanier, S., Prince, A., and Huletsky, A. 1997. Characterization of the pen $A$ and penR genes of Burkholderia cepacia 249 which encode the chromosomal class A penicillinase and its LysR-type transcriptional regulator. Antimicrob. Agents Chemother. 41:2399-2405.

14. Aronoff, S.C. 1988. Outer membrane permeability in Psendomonas cepacia: diminished porin content in a $\beta$-lactam-resistant mutant and in resistant cystic fibrosis isolates. Antimicrob. Agents Chemother. 32:1636-1639.

15. Parr, T.R., Jr., Moore, R.A., Moore, L.V., and Hancock, R.E.W. 1987. Role of porins in intrinsic antibiotic resistance of Psendomonas cepacia. Antimicrob. Agents Chemother. 31:121-123.
16. Burns, J.L., Hedin, L.A., and Lien, D.M. 1989. Chloramphenicol resistance in Pseudomonas cepacia because of decreased permeability. Antimicrob. Agents Chemother. 33:136-141.

17. Zhang, L., Li, X.Z., and Poole, K. 2001. Fluoroquinolone susceptibilities of efflux-mediated multidrug-resistant Psendomonas aeruginosa, Stenotrophomonas maltophilia and Burkholderia cepacia. J. Antimicrob. Chemother. 48:549-552.

18. Nikaido, H. 1998. Antibiotic resistance caused by gram-negative multidrug efflux pumps. Clin. Infect. Dis. 27:S32-S41.

19. Chuanchuen, R., et al. 2001. Cross-resistance between triclosan and antibiotics in Pseudomonas aeruginosa is mediated by multidrug efflux pumps: exposure of a susceptible mutant strain to triclosan selects $n f x B$ mutants overexpressing MexCD-OprJ. Antimicrob. Agents Chemother. 45:428-432.

20. Kohler, T., et al. 1997. Characterization of MexE-MexF-OprN, a positively regulated multidrug efflux system of Psendomonas aernginosa. Mol. Microbiol. 23:345-354.

21. Kohler, T., et al. 1996. Multidrug efflux in intrinsic resistance to trimethoprim and sulfamethoxazole in Pseudomonas aeruginosa. Antimicrob. Agents Chemother. 40:2288-2290.

22. Paulsen, I.T., Brown, M.H., and Skurray, R.A. 1996. Proton-dependent multidrug efflux systems. Microbiol. Rev. 60:575-608.

23. Masuda, N., Gotoh, N., Ohya, S., and Nishino, T. 1996. Quantitative correlation between susceptibility and OprJ production in $\mathrm{NfxB}$ mutants of Pseudomonas aeruginosa. Antimicrob. Agents Chemother. 40:909-913.

24. Moore, R.A., DeShazer, D., Reckseidler, S., Weissman, A., and Woods, D. 1999. Efflux-mediated aminoglycoside and macrolide resistance in Burkholderia pseudomallei. Antimicrob. Agents Chemother. 43:465-470.

25. Nikaido, H. 1996. Multidrug efflux pumps of gram-negative bacteria. J. Bacteriol. 178:5853-5859.

26. Poole, K., Krebes, K., McNally, C., and Neshat, S. 1993. Multiple antibiotic resistance in Pseudomonas aeruginosa: evidence for involvement of an efflux operon. J. Bacteriol. 175:7363-7372.

27. Walsh, C. 2000 . Molecular mechanisms that confer antibacterial drug resistance. Nature. 406:775-781.

28. Li, X., Zhang, Z.L., and Poole, K. 1998. Role of the multidrug efflux systems of Pseudomonas aeruginosa in organic solvent tolerance. J. Bacteriol. 180:2987-2991.

29. Burns, J.L., Wadsworth, C.D., Barry, J.J., and Goodall, C.P. 1996. Nucleotide sequence analysis of a gene from Burkholderia (Pseudomonas) cepacia encoding an outer membrane lipoprotein involved in multiple antibiotic resistance. Antimicrob. Agents Chemother. 40:307-313.

30. Sambrook, J., Fritsch, E.F., and Maniatis, T. 1989. Molecular cloning: a laboratory manual. 2nd edition. Cold Spring Harbor Laboratory Press. Cold Spring Harbor, New York, USA.

31. National Committee for Clinical Laboratory Standards. 1997. Methods for dilution antimicrobial susceptibility tests for bacteria that grow aerobically, $4^{\text {th }}$ ed. Approved standard M7-A4. National Committee for Clinical Laboratory Standards. Villanova, Pennsylvania, USA.

32. Mahenthiralingam, E., et al. 2000. DNA-Based diagnostic approaches for identification of Burkholderia cepacia complex, Burkholderia vietnamiensis, Burkholderia multivorans, Burkholderia stabilis, and Burkholderia cepacia genomovars I and III. J. Clin. Microbiol. 38:3165-3173.

33. Totten, P.A., and Lory, S. 1990. Characterization of the type A flagellin gene from Pseudomonas aeruginosa PAK. J. Bacteriol. 172:7188-7199.

34. Miller, J.H. 1972. Experiments in molecular genetics. Cold Spring Harbor Laboratory Press. Cold Spring Harbor, New York, USA. 466 pp.

35. Sokol, P.A. 1986. Production and utilization of pyochelin by clinical isolates of Pseudomonas cepacia. J. Clin. Microbiol. 23:560-562.

36. Haas, B., Kraut, J., Marks, J., Zanker, S.C., and Castignetti, D. 1991. Siderophore presence in sputa of cystic fibrosis patients. Infect. Immun. 59:3997-4000.

37. Burns, J.L., and Clark, D.K. 1992. Salicylate inducible antibiotic resistance in Pseudomonas cepacia associated with absence of a pore-forming outer membrane protein. Antimicrob. Agents Chemother. 36:2280-2285.

38. Li, X.Z., Livermore, D.M., and Nikaido, H. 1994. Role of efflux pump(s) in intrinsic resistance of Pseudomonas aeruginosa: resistance to tetracycline, chloramphenicol and norfloxacin. Antimicrob. Agents Chemother. 38:1732-1741.

39. Mahenthiralingam, E., et al. 2000. Diagnostically and experimentally useful panel of strains from the Burkholderia cepacia complex. J. Clin. Microbiol. 38:910-913.

40. Altschul, S.F., et al. 1997. Gapped BLAST and PSI-BLAST: a new generation of protein database search programs. Nucleic Acids Res. 25:3389-3402.

41. Tusnady, G.E., and Simon, I. 1998. Principles governing amino acid composition of integral membrane proteins: applications to topology prediction. J. Mol. Biol. 283:489-506.

42. Schell, M.A. 1993. Molecular biology of the LysR family of transcriptional regulators. Annu. Rev. Microbiol. 47:597-626.

43. Nakashita, H., Kozuka, K., Hidaka, T., Hara, O., and Seto, H. 2000. Identification and expression of the gene encoding phosphonopyruvate 
decarboxylase of Streptomyces bygroscopicus. Biochim. Biophys. Acta. 1490:159-162.

44. Tsujita, T., Ninomiya, H., and Okuda, H. 1989. p-Nitrophenyl butyrate hydrolyzing activity of hormone sensitive lipase from bovine adipose tissue. J. Lipid Res. 30:997-1004.

45. Jorgensen, S.K., Skov, W., and Diderichsen, B. 1991. Cloning, sequence and expression of a lipase gene from Psendomonas cepacia: lipase production in heterologous hosts requires two Pseudomonas genes. J. Bacteriol. 173:559-567.

46. Sugihara, A., Ueshima, M., Shimada, Y., Tsunasawa, S., and Tominaga, Y. 1992. Purification and characterization of a novel thermostable lipase from Pseudomonas cepacia. J. Biochem. (Tokyo). 112:598-603.

47. Nakai, K., and Kanehisa, M. 1991. Expert system for predicting protein localization sites in Gram-negative bacteria. Proteins. 11:95-110.

48. Von Heijne, G. 1986. A new method for predicting signal sequence cleavage sites. Nucleic Acids Res. 14:4683-4690.

49. Sokol, P.A., Lewis, C.J., and Dennis, J.J. 1992. Isolation of a novel siderophore from Psendomonas cepacia. J. Med. Microbiol. 36:184-189.

50. Wigfield, S.M., et al. 2002. Identification of an immunodominant drug efflux pump in Burkholderia cepacia. J. Antimicrob. Chemother. 49:619-624.

51. Holmes, A., Govan, J., and Goldstein, R. 1998. Agricultural use of Burkholderia (Pseudomonas) cepacia: a threat to human health? Emerg. Infect. Dis. 4:221-227.
52. Lessie, T.G., Hendrickson, W., Manning, B.D., and Devereux, R. 1996 Genomic complexity and plasticity of Burkholderia cepacia. FEMS Microbiol. Lett. 144:117-128.

53. Sangodkar, U., Chapman, P., and Chakrabarty, A. 1988. Cloning, physical mapping and expression of chromosomal genes specifying degradation of the herbicide 2,4,5-T by Pseudomonas cepacia AC1100. Gene. 71:267-277.

54. Hardy, P.C., Ederer, G.M., and Matsen, J.M. 1972. Contamination of commercially packaged urinary catheter kits with the pseudomonad EO-1. N. Engl. J. Med. 282:33-35.

55. Panlilio, A.L., et al. 1992. Infections and pseudoinfections due to povidone-iodine solution contaminated with Pseudomonas cepacia. Clin. Infect. Dis. 14:1078-1083.

56. Köhler, T., Epp, S.F., Curty, L.K., and Pechére, J.C. 1999. Characterization of MexT, the regulator of the MexE-MexF-OprN multidrug efflux system of Pseudomonas aeruginosa. J. Bacteriol. 181:6300-6305.

57. Baker, B., Zambryski, P., Staskawicz, B., and Dinesh-Kumar, S.P. 1997. Signaling in plant-microbe interactions. Science. 276:726-733.

58. Delaney, T.P., et al. 1994. A central role of salicylic acid in plant disease resistance. Science. 266:1247-1250

59. Furrer, J.L., Sanders, D.N., Hook-Barnard, I.G., and McIntosh, M.A. 2002. Export of the siderophore enterobactin in Escherichia coli: involvement of a 43 kDa membrane exporter. Mol. Microbiol. 44:1225-1234. 